Article

\title{
Comparison of Antioxidant Properties of Refined and Whole Wheat Flour and Bread
}

\author{
Lilei Yu ${ }^{1}$, Anne-Laure Nanguet ${ }^{1,2}$ and Trust Beta ${ }^{1,3, *}$
}

1 Department of Food Science, University of Manitoba, Winnipeg, MB R3T 2N2, Canada;

E-Mails: umyul@cc.umanitoba.ca (L.Y.); annelaure.nanguet@yahoo.fr (A.-L.N.)

2 Higher Engineering School in Agri-Food Integrated Development (ESIROI), Sainte-Clotilde, Reunion Island 97490, France

3 Richardson Centre for Functional Foods \& Nutraceuticals, Smartpark, University of Manitoba, Winnipeg, MB R3T 2N2, Canada

* Author to whom correspondence should be addressed; E-Mail: Trust.Beta@umanitoba.ca; Tel.: +1-204-474-8214; Fax: +1-204-474-7630.

Received: 14 August 2013; in revised form: 13 November 2013 / Accepted: 14 November 2013 / Published: 26 November 2013

\begin{abstract}
Antioxidant properties of refined and whole wheat flour and their resultant bread were investigated to document the effects of baking. Total phenolic content (TPC), 2,2-diphenyl-1-picrylhydrazyl (DPPH) radical scavenging activity and oxygen radical absorbance capacity (ORAC) were employed to determine the content of ethanol extractable phenolic compounds. HPLC was used to detect the presence of phenolic acids prior to their confirmation using LC-MS/MS. Whole wheat flour showed significantly higher antioxidant activity than refined flour $(p<0.05)$. There was a significant effect of the bread-making process with the TPC of whole wheat bread $(1.50-1.65 \mathrm{mg} / \mathrm{g})$ and white bread $(0.79-1.03 \mathrm{mg} / \mathrm{g})$ showing a respective reduction of $28 \%$ and $33 \%$ of the levels found in whole wheat and refined flour. Similarly, baking decreased DPPH radical scavenging capacity by $32 \%$ and $30 \%$. ORAC values, however, indicated that baking increased the antioxidant activities of whole wheat and refined flour by 1.8 and 2.9 times, respectively. HPLC analysis showed an increase of $18 \%$ to $35 \%$ in ferulic acid after baking to obtain whole and refined wheat bread containing 330.1 and $25.3 \mu \mathrm{g} / \mathrm{g}$ (average), respectively. Whole wheat flour and bread were superior to refined flour and bread in in vitro antioxidant properties.
\end{abstract}

Keywords: wheat; whole wheat flour; refined flour; bread; antioxidant activity; ferulic acid 


\section{Introduction}

Recently, epidemiological studies have shown that the consumption of whole grains and grain-based products is associated with the reduced risk of oxidative-stress related chronic diseases and age-related disorders, such as cardiovascular diseases, carcinogenesis, type II diabetes and obesity [1]. Parts of the health benefits of whole grain flours are attributed to the presence of antioxidants. In addition to the most common antioxidants, such as vitamin $\mathrm{C}$ (tocopherols and tocotrienols), vitamin $\mathrm{E}$ and carotenoids [2], grains also contain some phyto-antioxidants, including phenolic acids and flavonoids [3]. The most abundant antioxidants in whole grains are phenolic acids, which are highly concentrated in the bran and the germ [2], both of which are removed to obtain refined flour. Phenolic acids exist as free, esterified and insoluble-bound forms [4]. One of the advantages of bound phytochemicals is their ability to survive digestion in the upper gut, allowing them to reach the colon and, therefore, exert health benefits [5]. Phenolic compounds present in cereals are primarily ester-linked to cell wall polymers representing $80 \%-95 \%$ of the total amount [6]. Ferulic acid is one example with free, conjugated and bound forms in the ratio of 0.1:1:100 [5]. The cell wall bound phenolics are alkali labile [7]. Therefore different extraction procedures are needed to obtain free and bound phenolic acids.

Unlike laboratory milled flour, commercially milled flour often contains other additives, for example, ascorbic acid, amylase and azodicarbonamide in whole wheat flour. In comparison, to obtain refined flour, the nutrient-rich components of wheat, namely the bran and germ, are usually removed. These components contain phenolic acids, such as ferulic acid and caffeic acid, as well as some other compounds, including phytic acid, vitamin $\mathrm{E}$ and selenium, which all contribute to the antioxidant properties of the flour. To compensate for the loss of nutrients, government regulations dictate the addition of vitamins and minerals into these flours and label the modified flour as refined flour. These additives are primarily niacin, reduced iron, thiamine mononitrate, riboflavin and folic acids [8]. As practiced with whole wheat flour, ascorbic acid, amylase and azodicarbonamide are also added.

Commercial flour as the direct raw material that consumers can get from the marketplace needs further exploration of its potential health benefits in terms of antioxidant properties. Even though additives may exert antioxidant effects, they still differ from natural sources on a chemical and biochemical level. Moreover, the bread making process is believed to compromise the nutrient content, for example, leading to the loss of $30 \%$ of vitamin $\mathrm{E}$ [9]. The literature also indicates that the non-nutrient substances, phenolic acids, are labile to high temperature [10]. On the contrary, baking has been reported to increase the antioxidant activity of wholemeal bread compared with its flour and that the crust of white bread contained slightly more phenolic compounds than the crumb, because of the Maillard reaction [11]. Therefore, the objective of this study was to investigate the antioxidant properties of whole wheat and refined flours and the effect of the baking process on their resultant breads.

\section{Experimental Section}

\subsection{Materials and Chemicals}

Five brands of flours were selected on the basis that each brand contains whole wheat and refined (enriched, white) flour. These brands were namely Robin Hood (Smucker Foods of Canada 
Corporation, Markham, ON, Canada), Rogers (Rogers Foods Limited, Armstrong, BC, Canada), No Name (Loblaws Inc., Calgary, AB, Canada), Great Value (Wal-Mart Stores, Inc., San Bruno, CA, USA) and Compliments (Sobeys Inc., Whitby, ON, Canada).

Phenolic acid standards (gallic, protocatechuic, p-hydroxybenzoic, vanillic, caffeic, syringe, p-coumaric, ferulic, sinapic, iso-ferulic, o-coumaric, trans-cinnamic acid) were used for phenolic acid identification, and only ferulic acid was quantified (Sigma-Aldrich Chemical Co., St. Louis, MO, USA). Folin-Ciocalteu reagent, 2,2-diphenyl-1-picrylhydrazyl (DPPH), 2,20-azobis (2-methylpropionamide) dihydrochloride (AAPH) and 6-hydroxy-2,5,7,8-tetramethychroman-2carboxylic acid (Trolox) were applied for antioxidant potential evaluation (Sigma-Aldrich Chemical Co., St. Louis, MO, USA). Ethanol, acetone and ethyl acetate were used for sample preparation and deionized distilled water, HPLC grade methanol and acetic acid were used in HPLC and HPLC-MS/MS analysis.

\subsection{Bread-Making Method}

Dough was prepared using an optimized straight-dough bread-making method [12]. Initially, $5.3 \mathrm{~g}$ yeast was dissolved in water and mixed with dry ingredients, including $6.0 \mathrm{~g}$ sucrose, $1.5 \mathrm{~g}$ salt and $3.0 \mathrm{~g}$ shortening. The latter was first melted prior to mixing with other ingredients. Then, $100 \mathrm{~g}$ of flour were added to the mixture contained inside the KitchenAid pin-type mixer (Whirlpool Corporation, Benton Charter Township, MI, USA) at low speed for $2 \mathrm{~min}$, followed by 6 min of high speed mixing. During mixing, water was added, depending on the type of flour, to reach the point of minimum mobility. After adequate mixing of the dough, it was placed in a water bath at a temperature of $30{ }^{\circ} \mathrm{C}$. After $90 \mathrm{~min}$ rest, the dough was punched manually and rolled using a rolling pin before incubating for $52 \mathrm{~min}$. A second punch was done followed by $25 \mathrm{~min}$ incubation. Afterwards, dough was shaped and incubated for the last $33 \pm 2 \mathrm{~min}$ of proof to a desired height. The oven was preheated to the set temperature of $215{ }^{\circ} \mathrm{C}$ prior to baking the dough for $24 \mathrm{~min}$. Each sample was baked in two batches, and the average value was reported.

\subsection{Sample Preparation}

The bread produced from the above flour materials was freeze-dried and ground. Both raw flours and ground bread were milled to pass through a $0.5 \mathrm{~mm}$ sieve. Raw flours were measured on an as is basis, and their moisture contents were used to convert the results to a dry basis.

\subsection{Extraction of Soluble Phenolic Compounds}

The antioxidant components of both raw flours and ground bread samples were extracted following the method according to Li et al. [13] with some modifications. One gram finely ground flour was mixed with $10 \mathrm{~mL} 1 \mathrm{~N} \mathrm{HCl} / 95 \%$ ethanol (v/v, 15/85) solvent in an amber bottle under nitrogen. The mixture was vortexed. Then, extraction was performed in a temperature-controlled $\left(65^{\circ} \mathrm{C}\right)$ water bath shaker (VWR International, Radnor, PA, USA) at a constant speed for $80 \mathrm{~min}$. The resulting mixture was centrifuged at $7800 \times \mathrm{g}\left(10,000 \mathrm{rpm}\right.$ at $5{ }^{\circ} \mathrm{C}$ for $\left.15 \mathrm{~min}\right)$. The supernatant was collected and stored in the dark at $-20^{\circ} \mathrm{C}$ until their use for determination of total phenolic content (TPC), DPPH radical 
$(\mathrm{DPPH} \bullet)$ scavenging activity and oxygen radical absorbance capacity (ORAC). Extraction was done in duplicate for both raw flours and ground bread samples. For HPLC analysis of acidified ethanol extract, the collected supernatant was further dehydrated with $1 \mathrm{~g}$ of $\mathrm{Na}_{2} \mathrm{SO}_{4}$ and then filtered with filter paper (125 $\mathrm{mm} \varphi$, Whatman ${ }^{\mathrm{TM}}$ Cat No. 1004 125). The dehydrated samples were concentrated under vacuum using a rotary evaporator (RE-51 Rotary Evaporator, Yamato Scientific America, Inc., Santa Clara, CA, USA). The dried phenolic extract was redissolved in $2 \mathrm{~mL}$ of $50 \%$ ethanol and filtered with a $0.45 \mu \mathrm{m}$ syringe filter before HPLC analysis for phenolic acids. Extraction was done in duplicate for raw flours and ground bread samples.

\subsection{Total Phenolic Content Determination}

Total phenolic content of each extract was determined using the Folin-Ciocalteu method as described by Li et al. [13]. Briefly, a 10-fold dilution of Folin-Ciocalteu reagent was prepared just prior to use. Then, $1.5 \mathrm{~mL}$ of freshly diluted Folin-Ciocalteu reagent was used to oxidize $0.2 \mathrm{~mL}$ sample extracts. After allowing the mixture to equilibrate for $5 \mathrm{~min}$, the reaction was then neutralized with $1.5 \mathrm{~mL}$ sodium carbonate solution $(60 \mathrm{~g} / \mathrm{L})$ at room temperature. The absorbance of the resulting solution was measured at $725 \mathrm{~nm}$ after 90 min against a blank of acidified ethanol $(1 \mathrm{~N} \mathrm{HCl} / 95 \%$ ethanol, v/v, 15/85). Ferulic acid was used as a standard. Therefore, the total phenolic content of samples was expressed as milligrams of ferulic acid equivalents $/ \mathrm{g}$.

\subsection{DPPH Radical Scavenging Activity Assay}

The DPPH method was used according to the modified method of Beta et al. [14]. A $60 \mu \mathrm{mol} / \mathrm{L}$ $\mathrm{DPPH} \bullet$ reactant was made in methanol. Then $3.9 \mathrm{~mL}$ of DPPH $\bullet$ solution was added to $0.1 \mathrm{~mL}$ of sample, and the absorbance at $515 \mathrm{~nm}$ was measured at $t=60 \mathrm{~min}$. To determine the absorbance at $t=0 \mathrm{~min}$, measurement was immediately taken after adding $3.9 \mathrm{~mL}$ of DPPH $\bullet$ solution to $0.1 \mathrm{~mL}$ methanol. The antioxidant activity was calculated as:

$$
\% \mathrm{DPPH} \bullet \text { scavenging activity }=\left(1-\left[A_{\text {sample,t }} / A_{\text {control, } \mathrm{t}=0}\right]\right) \times 100 .
$$

A plot of trolox concentration with \% DPPH• scavenging activity was used as the standard curve. Based on this curve, the concentrations of flour samples were expressed as micromole equivalent of trolox $/ \mathrm{g}$.

\subsection{Oxygen Radical Absorbance Capacity (ORAC) Assay}

The antioxidant activity was determined using the ORAC assay described by Huang et al. [15] with some modification. The assay was performed using an FLx800 microplate fluorescence reader, while the software, KC4 3.0, version 29, was used to control the program. Each well in the plate contained $150 \mu \mathrm{L}$ fluorescein with $25 \mu \mathrm{L}$ extracts or trolox standard and was incubated at $37^{\circ} \mathrm{C}$ for $15 \mathrm{~min}$. After incubation, $25 \mu \mathrm{L}$ AAPH was added to each well. The fluorescence intensity was then measured automatically by the reader and a regression equation between the trolox concentration and the net area under the fluorescence decay curve was obtained. Therefore:

$$
\mathrm{AUC}=0.5+f_{1} / f_{0}+\ldots+f_{\mathrm{i}} / f_{0}+\ldots+f_{49} / f_{0}+0.5 \times\left(f_{50} / f_{0}\right)
$$

where, $f_{0}=$ initial fluorescence reading at $0 \mathrm{~min}$ and $f \mathrm{i}=$ fluorescence reading at time $i$ min. 
The final results were expressed as trolox equivalent based on the standard curve.

\subsection{Extraction of Insoluble Phenolic Compounds after Alkaline Hydrolysis}

The bound phenolic compounds of both raw flours and ground bread samples were extracted following the method according to Chiremba et al. [16] with some modifications. A $200 \mathrm{mg}$ finely ground flour sample was extracted with $5 \mathrm{~mL}$ of $4 \mathrm{M} \mathrm{NaOH}$ using a $45 \mathrm{~mL}$ PTFE acid digestion bomb vessel (Parr Instrument Co., Moline, IL, USA). The bomb vessel was placed in a $1400 \mathrm{~W}$ domestic microwave oven (Diplomat model D811, Danby, Suweon, Korea). Samples were digested for $45 \mathrm{~s}$ at power 8 . The hydrolysate was adjusted to a $\mathrm{pH}$ of 1.8-2.0 using $6 \mathrm{~N} \mathrm{HCl}$ and extracted two times with $25 \mathrm{~mL}$ of ethyl acetate for $15 \mathrm{~min}$ under magnetic stirring. Lastly, $20 \mathrm{~mL}$ of ethyl acetate were used to extract for $10 \mathrm{~min}$. The organic phase (supernatant) was removed with a separating funnel. Further dehydration was performed by adding $1 \mathrm{~g}$ of $\mathrm{Na}_{2} \mathrm{SO}_{4}$ and then filtered with a filter paper $(125 \mathrm{~mm} \varphi$, Whatman ${ }^{\mathrm{TM}}$ Cat No. 1004 125). The extract was concentrated under vacuum using a rotary evaporator (RE-51 Rotary evaporator, Yamato Scientific America, Inc., Santa Clara, CA, USA). The dried phenolic extract was redissolved in $2 \mathrm{~mL}$ of $50 \%$ ethanol and filtered with a $0.45 \mu \mathrm{m}$ syringe filter before HPLC analysis for bound phenolic acids. Extraction was done in duplicate for raw flours and ground bread samples.

\subsection{High Performance Liquid Chromatography (HPLC) Analysis}

HPLC analysis of phenolic acids was performed on a Waters model 600 pump and controller with a Waters 2489 UV/visible detector (Waters Corp., Milford, MA, USA) according to Hirawan et al. [17]. A Gemini $5 \mu \mathrm{C} 18110$ A column was used $(150 \times 4.60 \mathrm{~mm})$ (Phenomenex, Torrance, CA, USA), and the solvents were $1 \%$ acetic acid in water (solvent A) and $1 \%$ acetic acid in methanol (solvent $\mathrm{B}$ ). Phenolic acid separation was achieved using a 30-min linear solvent gradient at a flow rate of $1.0 \mathrm{~mL} / \mathrm{min}$. The solvent gradient was as follows: at $0 \mathrm{~min}, 80 \% \mathrm{~A}, 20 \% \mathrm{~B} ; 0-8 \mathrm{~min}, 78 \% \mathrm{~A}, 22 \% \mathrm{~B}$; 8-10 min, 74\% A, 26\% B; 10-22 min, 73\% A, 27\% B; 22-24 min, 80\% A, 20\% B. The detector was set at $320 \mathrm{~nm}$ and $280 \mathrm{~nm}$. The injection volume was $10 \mu \mathrm{L}$. Identification of phenolic acids was achieved by comparison of the retention time of the phenolic acid standards and samples spiked with phenolic acid standards. Ferulic acid quantitation was based on the standard curves, and the peak area was used for calculations. The precision, validity and repeatability of the HPLC method were checked on an inter- and intra-day basis. The coefficient of variation was less than 0.05 . The limit of detection was $0.1 \mu \mathrm{g} / \mathrm{mL}$. The concentrations of standards used for the calibration curve were $0.5 \mu \mathrm{g} / \mathrm{mL}$, $1.0 \mu \mathrm{g} / \mathrm{mL}, 5 \mu \mathrm{g} / \mathrm{mL}, 10 \mu \mathrm{g} / \mathrm{mL}, 50 \mu \mathrm{g} / \mathrm{mL}, 100 \mu \mathrm{g} / \mathrm{mL}, 150 \mu \mathrm{g} / \mathrm{mL}, 200 \mu \mathrm{g} / \mathrm{mL}, 250 \mu \mathrm{g} / \mathrm{mL}$ and $500 \mu \mathrm{g} / \mathrm{mL}$. The HPLC analyses were done in duplicate.

\subsection{0. $L C-M S / M S$}

The chromatographic separation was carried out according to Hirawan et al. [18] on an HPLC (Waters 2695) system equipped with a photodiode array detector (PDA) (Waters 2695) and autosampler (Waters 717 plus) and coupled to a quadrupole time-of-flight mass spectrometer (Q-TOF MS) (Waters Corp, Milford, MA, USA). The analytical column was a $150 \times 4.60 \mathrm{~mm}$, Gemini 
$5 \mu \mathrm{C} 18110 \AA$ Å column (Phenomenex, Torrance, CA, USA). The mobile phase consisted of solvent A (1\% acetic acid in water) and solvent $\mathrm{B}$ (1\% acetic acid in methanol). Prior to introduction into the Q-TOF MS, the same 30 min linear solvent gradient was programmed to elute the sample through the column with a flow rate of $1.0 \mathrm{~mL} / \mathrm{min}$. A $10 \mu \mathrm{L}$ sample solution was loaded and injected by the autosampler. The Q-TOF MS was calibrated with sodium iodide for the negative mode through the mass range of 100-1500. Full mass spectra were recorded in negative mode by using the capillary voltage of $700 \mathrm{~V}$ and a cone voltage of $30 \mathrm{~V}$. The flow rates of desolvation gas $\left(\mathrm{N}_{2}\right)$ and cone gas $\left(\mathrm{N}_{2}\right)$ were $900 \mathrm{~L} / \mathrm{h}$ and $50 \mathrm{~L} / \mathrm{h}$, respectively. The desolvation temperature and the source temperature were set at $300{ }^{\circ} \mathrm{C}$ and $150{ }^{\circ} \mathrm{C}$, respectively. The MS/MS spectra were acquired by using collision energy of $20 \mathrm{~V}$.

\subsection{Statistical Analysis}

The experimental data were subjected to an analysis of variance using the SAS statistical software, version 9.3 (SAS Institute Inc., Cary, NC, USA). All data were reported as the means \pm standard deviation (SD) of duplicate analyses. Scheffe's test was used to determine the significant differences amongst flour and bread sample means at the level of $0.05(p<0.05)$.

\section{Results and Discussion}

\subsection{Total Phenolic Content of Solvent Extractible Compounds}

Total phenolic content (TPC) was expressed as milligrams of ferulic acid equivalent (FAE) per gram (mg/g) of dry flour samples (Figure 1a). Ferulic acid, the major phenolic acid found in wheat, was used as a standard. The TPC of refined flours, which ranged from 1.16 to $1.55 \mathrm{mg}$ FAE/g (mean $1.31 \mathrm{mg} \mathrm{FAE} / \mathrm{g}$ ), were significantly lower than those of whole wheat flours (range 2.10 to $2.35 \mathrm{mg}$ $\mathrm{FAE} / \mathrm{g}$, mean $2.20 \mathrm{mg} \mathrm{FAE} / \mathrm{g}$ ).

The antioxidant activities of the commercial wheat flours were higher than values reported for the flours milled from soft and hard wheat. The TPC of organic-solvent extractable phenolic compounds was reported to be $0.353 \mathrm{mg} \mathrm{FAE} / \mathrm{g}$ for hard whole wheat flour and $0.478 \mathrm{mg} \mathrm{FAE} / \mathrm{g}$ for soft whole wheat flour, while white wheat flours contained $0.137 \mathrm{mg} \mathrm{FAE} / \mathrm{g}$ and $0.161 \mathrm{mg} \mathrm{FAE} / \mathrm{g}$ for hard and soft wheat, respectively [19]. The lower values presented could be attributed to the defatting step, which removed some lipophilic phenolic compounds. Liu and others [20] reported the TPC of six different bread wheat (Triticum aestivum) grains. The values ranged from 1.46 to $2.26 \mathrm{mg} / \mathrm{g}$, which were similar to our results. Significant differences were detected among different brands, indicating that these wheat flours may exhibit different levels of antioxidant activities.

The average TPC for bread made from whole wheat and refined flour were 1.58 and $0.87 \mathrm{mg} \mathrm{FAE} / \mathrm{g}$, respectively. The lower TPCs of 1.01 and $0.52 \mathrm{mg} \mathrm{FAE} / \mathrm{g}$ have been reported, respectively, for purple wheat bread from whole and refined flour [21]. Overall, the TPC of bread decreased to about $72 \%$ and $67 \%$ of the average content found in whole wheat and refined flour. This was likely due to the loss of some phenolic acids, which have been reported as labile to baking, and the loss of some reducing vitamins, such as vitamin $\mathrm{C}$ (including ascorbic acid, which was added as a mandatory vitamin enrichment) [10,22]. 
Figure 1. (a) Total phenolic content (TPC) (b) 2,2-diphenyl-1-picrylhydrazyl (DPPH) radical scavenging activity and (c) oxygen radical scavenging absorbance capacity (ORAC) of soluble phenolic compounds from flours and corresponding breads *.

(a)

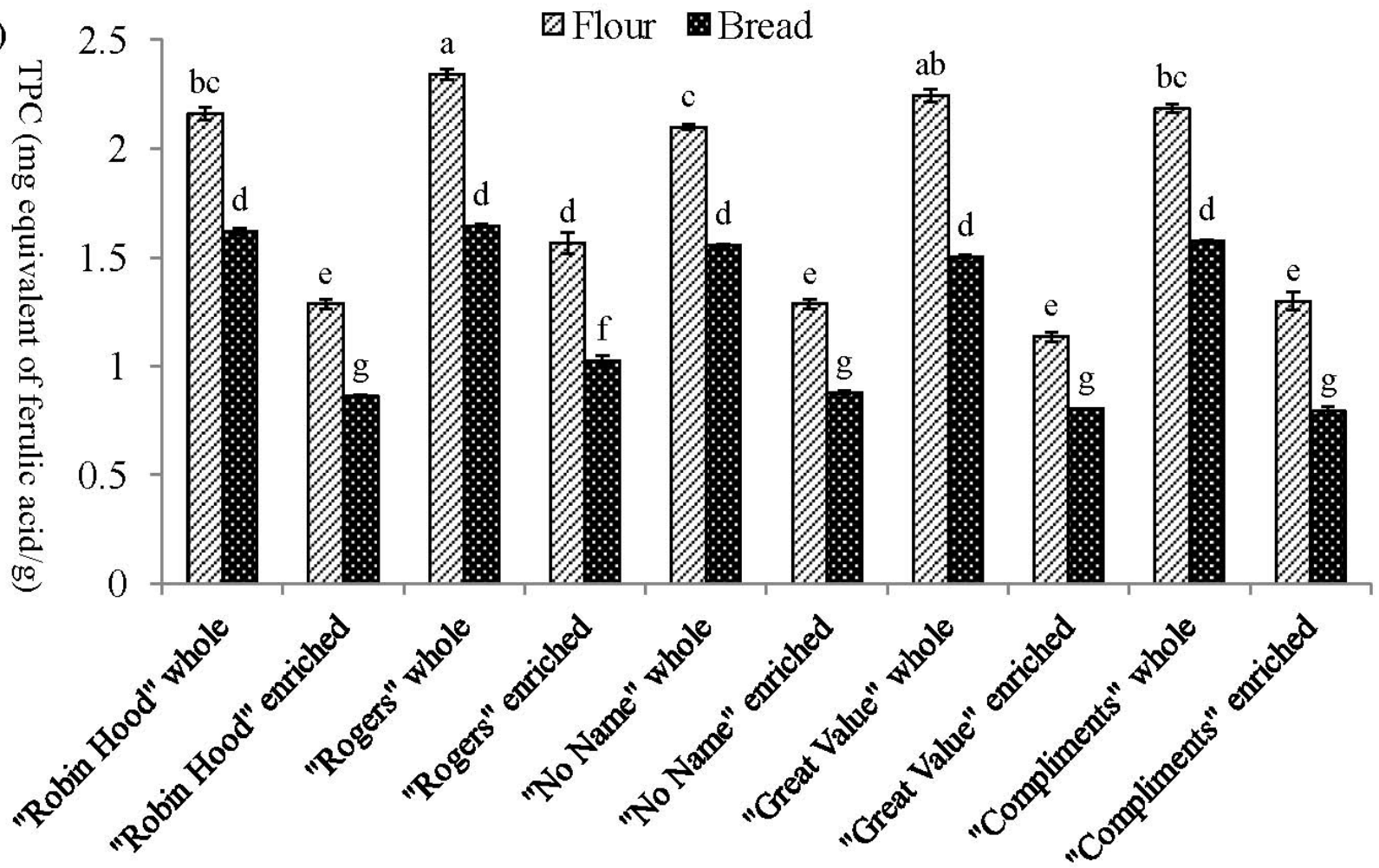

(b)

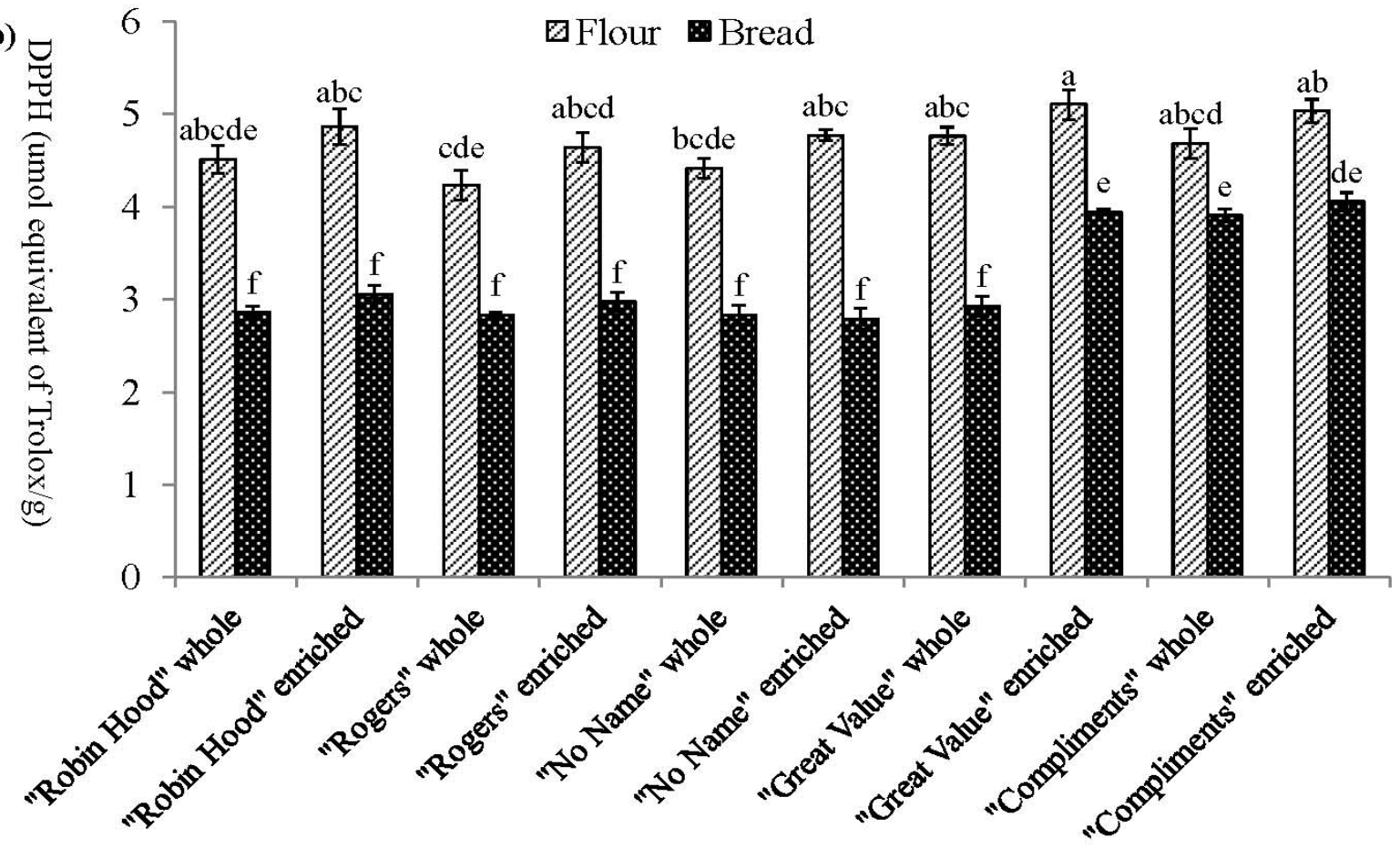


Figure 1. Cont.

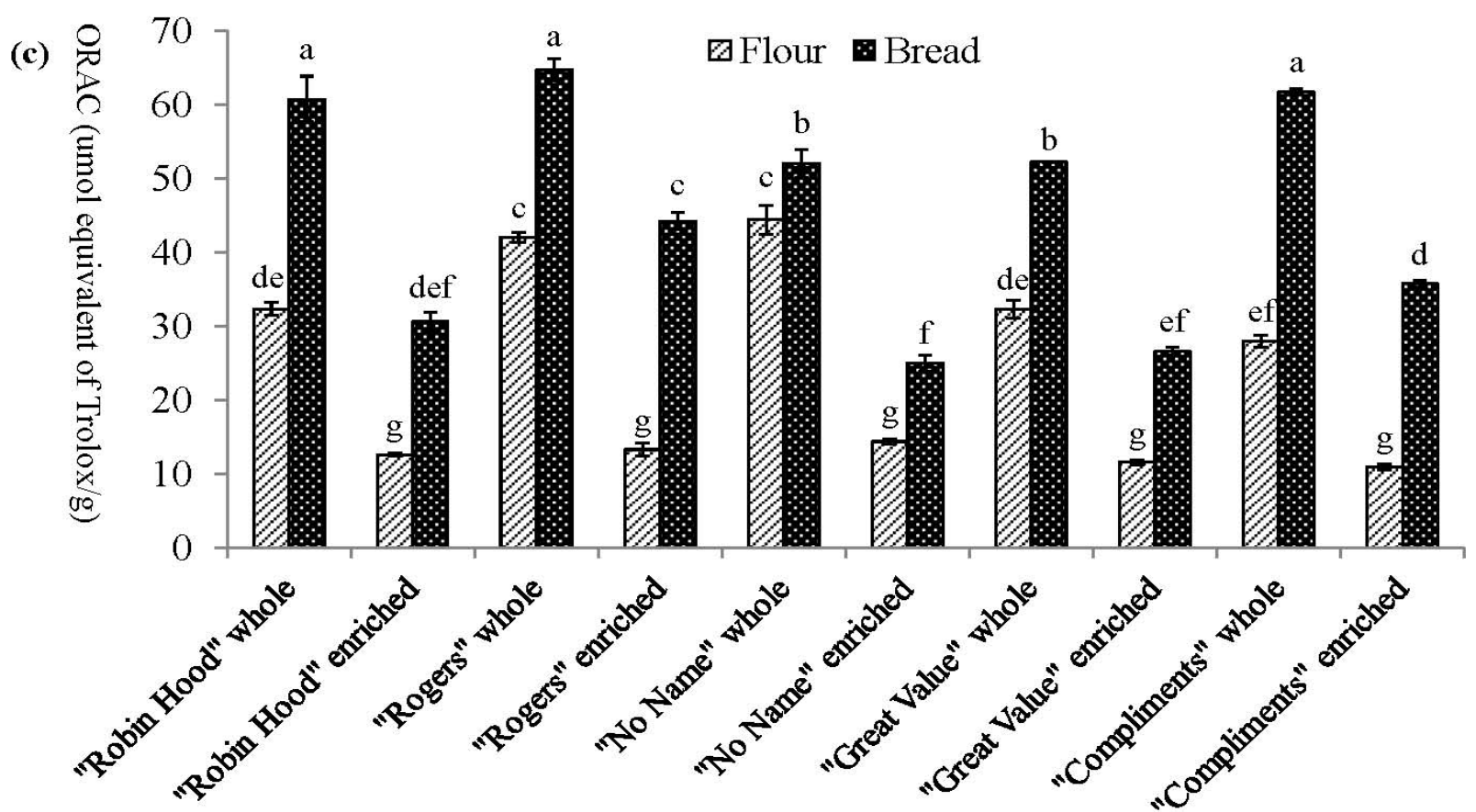

* Results are obtained based on acidified aqueous ethanol-soluble extracts and expressed as mean \pm standard deviation; Different letters in each bar are significantly different at $p<0.05$ (Scheffe's test).

\subsection{DPPH Radical Scavenging Activity of Soluble Phenolic Compounds}

The DPPH radical scavenging activities of flour samples were expressed as micromole trolox equivalents per gram $(\mu \mathrm{mol} \mathrm{TE} / \mathrm{g})$ of dried flours. The results are summarized in Figure $1 \mathrm{~b}$. Refined flours (range 4.59 to $5.00 \mu \mathrm{mol} \mathrm{TE} / \mathrm{g}$, mean $4.82 \mu \mathrm{mol} \mathrm{TE} / \mathrm{g}$ ) had slightly higher values than their whole wheat flour counterparts (range 4.28 to $4.77 \mu \mathrm{mol} \mathrm{TE} / \mathrm{g}$, mean $4.53 \mu \mathrm{mol} \mathrm{TE} / \mathrm{g}$ ), but the differences were not significant. Lavelli et al. [23] reported the radical scavenging activities of 63 einkorn wholemeal flours against the DPPH radical using water-saturated 1-butanol as the extracting solvent. The values $(0.58$ to $1.46 \mu \mathrm{mol} \mathrm{TE} / \mathrm{g})$ were significantly lower than our results. On the contrary, Liu and others [20] reported that the DPPH values for six different bread wheat grains ranged from $6.48 \pm 1.46 \mu \mathrm{mol} \mathrm{TE} / \mathrm{g}$ to $8.57 \pm 1.46 \mu \mathrm{mol} \mathrm{TE} / \mathrm{g}$, which were significantly higher than our results. The genetic and environmental factors, the processing conditions [24,25], as well as the extraction procedures may all affect the antioxidant levels of wheat flour.

The DPPH values for bread made from whole wheat flour ranged from 2.79 to $4.05 \mu \mathrm{mol} \mathrm{TE} / \mathrm{g}$ (mean $3.36 \mu \mathrm{mol} \mathrm{TE} / \mathrm{g}$ ), while bread made from refined flour ranged from 2.83 to 3.90, with mean $3.07 \mu \mathrm{mol} \mathrm{TE} / \mathrm{g}$. Again, bread made from refined flour had slightly higher values, except for "Great value", which had a significantly higher value.

During the bread making process, the average scavenging ability decreased by approximately $32 \%$ and $30 \%$, respectively, for whole wheat flour and refined flour. As explained above, the loss of scavenging ability could be attributed to the loss of some phenolic compounds, because the high temperature used during baking is known to cause the destruction of some phenolic acids [10]. Therefore, the extent of the decrease in DPPH scavenging abilities differed due to the different raw flour materials with varying phenolic contents. 


\subsection{Oxygen Radical Absorbance Capacity of Soluble Phenolic Compounds}

Similar to the DPPH free radical scavenging activity, the ORAC values were expressed as micromole trolox equivalent per gram $(\mu \mathrm{mol} \mathrm{TE} / \mathrm{g}$ ) of dry samples (Figure 1c). The refined flours (range 10.88 to $14.38 \mu \mathrm{mol} \mathrm{TE} / \mathrm{g}$, mean $12.52 \mu \mathrm{mol} \mathrm{TE} / \mathrm{g}$ ) showed significantly lower values compared to their whole wheat flour counterparts (range 27.93 to $44.33 \mu \mathrm{mol} \mathrm{TE} / \mathrm{g}$, mean $35.74 \mu \mathrm{mol} \mathrm{TE} / \mathrm{g}$ ) from the same brand.

The ORAC values of six varieties of wheat (hard/soft red spring, soft white/red winter, white spring durum and semi-hard red winter whole wheat grain) ranged from 19.58 to $37.49 \mu \mathrm{mol} \mathrm{TE} / \mathrm{g}$ dry weight [1]. Another study investigated the antioxidant capacity of Canada Western Red Spring (CWRS). The ORAC value of whole grain was $95 \pm 5 \mu \mathrm{mol} \mathrm{TE} / \mathrm{g}$, whilst that of white flour was $54 \pm 2 \mu \mathrm{mol} \mathrm{TE} / \mathrm{g}$ defatted material [26]. Compared with this literature, our results were in agreement with the previous study [1], but lower than those reported by the latter study [26]. Again, the genetic and environmental factors would affect the antioxidant levels of wheat [24].

ORAC values ranged from 51.89 to $64.65 \mu \mathrm{mol} \mathrm{TE} / \mathrm{g}$ (mean 58.20) and from 24.93 to $44.16 \mu \mathrm{mol}$ $\mathrm{TE} / \mathrm{g}$ (mean 32.31) for whole wheat bread and refined bread, respectively. The bread samples demonstrated significantly higher ORAC values, which were 1.8 times and 2.9 times higher than their corresponding flour counterparts. The ORAC method is used to evaluate the ability of an antioxidant to scavenge the peroxyl free radicals [27]; therefore, phenolic compounds are more likely to be detected by this method through the donation of electrons. This also explains the reason for the increase in antioxidant activity after the bread making process, which was only detected by ORAC assay. Gelinas and McKinnon [11] also observed that the crust of white bread contained more phenolic compounds than the crumb, because of the Maillard reaction, and this phenomenon was better illustrated in white bread than wholemeal bread.

According to Lin et al. [28], the improvement in antioxidant activity of wheat bread might be due to the incorporation of phenolic compounds, mainly rutin and quercetin; however, there was no further explanation of the incorporation. As Gelinas and McKinnon [11] indicated, Maillard reaction products (MRP) resulting from the Maillard reaction, a well-known non-enzymatic browning reaction, exhibited in vitro antioxidant activities. The Maillard reaction involves the interaction between amino acids and reducing sugars or lipid oxidation products [29]. The furan ring and nitrogen containing brown compounds (melanoidins) contributed to the antioxidant properties of baked grain products [30]. Water-soluble MRP, especially melanoidins, have been reported to have antioxidant activity according to the recently developed oxygen radical scavenging or chelating metal assays [29]. MRP could be another reason for the increase in antioxidant activity after baking, as detected only through the ORAC method. Moreover, Yilmaz and Toledo [29] also indicated that various factors, such as the type of reactants, temperature, $\mathrm{pH}$, water activity and the availability of oxygen, could strongly influence the antioxidant properties of the MRP.

Michalska et al. [31] reported the antioxidant activity of rye bread using the ORAC assay. For whole bread, the ORAC value was $23.76 \pm 1.64 \mu \mathrm{mol} \mathrm{TE} / \mathrm{g}$, while for white bread, the value was $14.4 \pm 0.28 \mu \mathrm{mol} \mathrm{TE} / \mathrm{g}$ dry material. In addition, Moore and $\mathrm{Yu}$ [32] reported the results on ORAC values for whole wheat bread as $20 \mu$ moles $\mathrm{TE} / \mathrm{g}$ and for white wheat bread as $12 \mu \mathrm{moles} \mathrm{TE} / \mathrm{g}$. Compared with these values, our results were higher. Differences in the raw materials and bread 
making procedures could contribute to the discrepancies observed. The bread made by Michalska group was based on a longer fermentation time (totally $52 \mathrm{~h}$ ) and baked at higher temperature for a longer time ( $260^{\circ} \mathrm{C}$ for $40 \mathrm{~min}$ ). The long fermentation time might lead to the destruction of antioxidants through decomposition by microorganisms or exposure to the air. The high temperature and longer time also affect the antioxidant activity.

\subsection{Ferulic Acid Determination and Quantification Using HPLC}

In wheat flour samples, ferulic, p-coumaric and vanillic acids were found to be the major phenolic acids in free forms [1], while syringic and protocatechuic acids were present in small amounts [33]. However, by comparing the retention time with 11 phenolic standards, even ferulic acid could not be detected when acidified aqueous ethanol was used as the solvent (results not shown). This would be attributed to the fact that ethanol extract may have only free ferulic acid, which contributes $0.1 \%$ of the total ferulic acid content. As previously reported by Adom and Liu [5], the free, conjugated and bound ferulic acids are in the ratio of 0.1:1:100. Therefore, alkali hydrolysis was used to release bound phenolics.

Figure 2 shows the HPLC chromatograms of bound phenolic acids from "Great Value" whole wheat flour and its corresponding bread. According to the chromatograms, ferulic acid (FA) was the dominant acid with a retention time of $18.7 \mathrm{~min}$. Other peaks were too low and considered insignificant to demonstrate the effect of baking on flours. FA was the major phenolic acid in wheat grains (up to 85\%-90\%) [34] and present mostly in the bound form [35-37]. Thus, only ferulic acid (FA) was further quantified with HPLC. To confirm the identity, the LC-MS/MS spectra of the ferulic acid peaks in flour and bread were examined (Figure 2a',b'). Based on the molecular ions $[\mathrm{M}-\mathrm{H}]^{-}$and fragmentation patterns, ferulic acid $\left(\mathrm{m} / z\right.$ 193) provided a $[\mathrm{M}-\mathrm{H}-15]^{-}$anion radical at $m / z 178$, due to the loss of the $\mathrm{CH}_{3}$ group (15 Da). Other fragments were generated at $\mathrm{m} / z 149$ and 134 , due to the loss of $\mathrm{CO}_{2}(44 \mathrm{Da})$ and $\mathrm{CH}_{3} / \mathrm{CO}_{2}$ groups. These assignments agreed with the mass spectra reported earlier [16,38].

Figure 2. HPLC chromatograms of extracts of bound ferulic acid in the (a) flour sample and (b) bread sample and LC-MS/MS spectra of the (a') flour sample and (b') bread sample.

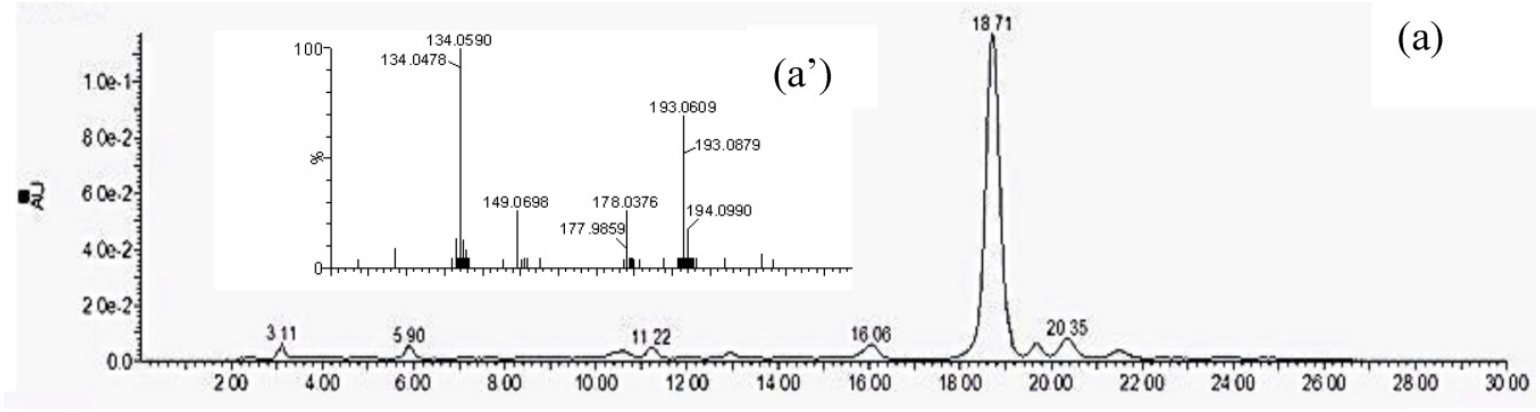


Figure 2. Cont.

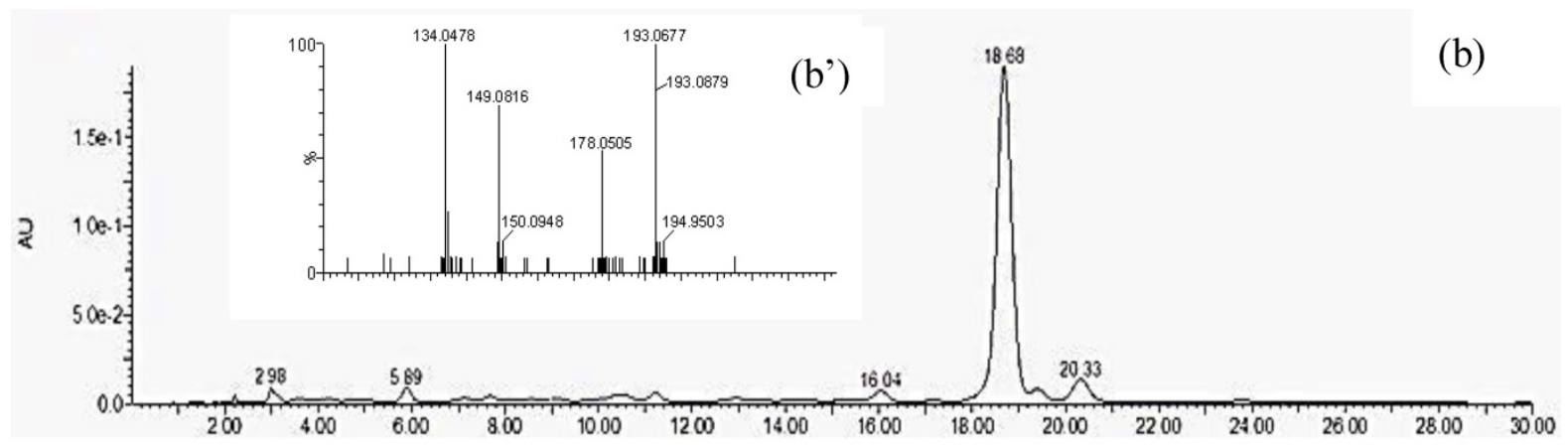

The FA contents of flour and bread products are shown in Table 1. Bound FA levels in whole wheat flours (mean $271.6 \mu \mathrm{g} / \mathrm{g}$ ) were significantly higher than in refined flours (mean $16.4 \mu \mathrm{g} / \mathrm{g}$ ), because whole wheat flours contain both bran and germ fractions. Previous studies also have shown that the wheat phenolics were mainly concentrated in the bran and germ fractions of wheat kernels [14,39]. Hung et al. [40] reported that the content of bound ferulic acid in two Canadian wheat classes (whole wheat) ranged from 368 to $605 \mu \mathrm{g} / \mathrm{g}$ of the sample, values higher than those found in the current commercial flours ( 248 to $313 \mu \mathrm{g} / \mathrm{g}$ sample). The difference in endogenous levels of bound ferulic acid between the commercial flours and the two Canadian wheat classes could be due to several factors, including variety, environmental conditions during field production and post-harvest handling.

Table 1. Bound ferulic acid content (micrograms of ferulic acid (FA)/g of dry sample) in flour and bread products.

\begin{tabular}{ccccc}
\hline Sample Name & $\begin{array}{c}\text { Whole } \\
\text { Wheat Flour }\end{array}$ & $\begin{array}{c}\text { Refined } \\
\text { Flour }\end{array}$ & $\begin{array}{c}\text { Bread Made from } \\
\text { Whole Wheat Flour }\end{array}$ & $\begin{array}{c}\text { Bread Made from } \\
\text { Refined Flour }\end{array}$ \\
\hline Robin Hood & $247.8^{\text {ef }}$ & $14.5^{\mathrm{g}}$ & $316.2^{\mathrm{cd}}$ & $20.0^{\mathrm{g}}$ \\
Rogers & $275.7^{\mathrm{def}}$ & $22.7^{\mathrm{g}}$ & $374.6^{\mathrm{ab}}$ & $46.2^{\mathrm{g}}$ \\
No Name & $290.2^{\mathrm{cde}}$ & $20.8^{\mathrm{g}}$ & $393.5^{\mathrm{a}}$ & $29.2^{\mathrm{g}}$ \\
Great Value & $313.1^{\mathrm{cd}}$ & $11.5^{\mathrm{g}}$ & $334.7^{\mathrm{bc}}$ & $17.7^{\mathrm{g}}$ \\
Compliments & $230.5^{\mathrm{f}}$ & $12.8^{\mathrm{g}}$ & $231.4^{\mathrm{f}}$ & $13.6^{\mathrm{g}}$ \\
\hline
\end{tabular}

Different letters in each bar are significantly different at a level of $p<0.05$ (Scheffe's test).

The contents of bound ferulic acid were significantly higher in whole wheat bread compared to whole wheat flours, except for "Great Value" and "Compliments". The increase was about 23\% on average. The baking process did not significantly affect the endogenous low levels of ferulic acid in refined flour. Our results were in agreement with the studies of Gelinas and McKinnon [11] and Han and Koh [10], which indicated that the antioxidant activities of phenolic acids slightly decreased during mixing, but increased during fermentation and the baking process. Moreover, the HPLC analysis also explained the observations made using the ORAC method, which showed a higher antioxidant activity of bread samples. 


\section{Conclusions}

Whole wheat flours demonstrated higher antioxidant activities than refined flours. They exhibited higher TPC, DPPH, ORAC and ferulic acid levels despite the presence of several additives in refined flour that partially compensate for the loss of germ and bran. The baking process reduced the TPC and DPPH scavenging capacity, but increased the ORAC values and ferulic acid content of bread. It appears that the bread making process released ferulic acid and enhanced compounds that scavenge the peroxyl free radicals, while destroying some of the reducing compounds that react with the Folin-Ciocalteu reagent and DPPH free radicals. The findings are in support of the body of literature that whole wheat products are likely to be more beneficial to consumers than the refined wheat products.

\section{Acknowledgments}

Financial support from the NSERC Discovery Grant and Canada Foundation for Innovation (CFI-Leaders Opportunity Funds and CFI-New Opportunity Funds) is greatly acknowledged. We are also thankful for the technical support from Alison Ser, Yang Qiu, Pat Kenyon, Lovemore Malunga and Victoria Ndolo of the Department of Food Science, University of Manitoba. Special thanks to S. Arntfield for her guidance during the initiation of this project.

\section{Conflicts of Interest}

The authors declare no conflict of interest.

\section{References}

1. Okarter, N.; Liu, C.; Sorrells, M.E.; Liu, R.H. Phytochemical content and antioxidant activity of six diverse varieties of whole wheat. Food Chem. 2010, 199, 249-257.

2. Miller, H.E.; Rigelhof, F.; Marquart, L.; Prakash, A.; Kanter, M. Antioxidant content of whole grain breakfast cereals, fruits and vegetables. J. Am. Coll. Nutr. 2000, 19, 312S-319S.

3. Liu, R.H. Whole grain phytochemical and health. J. Cereal Sci. 2007, 46, 207-219.

4. Jung, M.Y.; Jeon, B.S.; Bock, J.Y. Free, esterified, and insoluble-bound phenolic acids in white and red Korean ginsengs (Panax ginseng C.A. Meyer). Food Chem. 2002, 79, 105-111.

5. Adom, K.K.; Liu, R.H. Antioxidant activity of grains. J. Agric. Food Chem. 2002, 50, 6182-6187.

6. Serpen, A.; Gokmen, V.; Pellegrini, N.; Fogliano, V. Direct measurement of the total antioxidant capacity of cereal products. J. Cereal Sci. 2008, 48, 816-820.

7. Waldron, K.; Parr, A.J.; Ng, A.; Ralph, J. Cell wall esterified phenolic dimers: Identification and quantification by reverse phase high performance liquid chromatography and diode array detection. Phytochem. Anal. 1996, 7, 305-312.

8. Rubin, K.W. Whole grains. Food Serv. Dir. 2002, 15, 48.

9. Leenhardt, F.; Lyan, B.; Rock, E.; Boussard, A.; Potus, J.; Chanlliaud, E.; Remesy, C. Wheat lipoxygenase activity induces greater loss of carotenoids than vitamin $\mathrm{E}$ during breadmaking. J. Agric. Food Chem. 2006, 54, 1710-1715. 
10. Han, H.M.; Koh, B.K. Antioxidant activity of hard wheat flour, dough and bread prepared using various processes with the addition of different phenolic acids. J. Sci. Food Agric. 2011, 91, 604-608.

11. Gelinas, P.; McKinnon, C.M. Effect of wheat variety, farming site, and bread-baking on total phenolics. Int. J. Food Sci. Technol. 2006, 41, 329-332.

12. AACC International. Optimized Straight-Dough Bread-Making Method; AACC International Method 10-10.03; AACC International: St. Paul, MN, USA.

13. Li, W.; Pickard, M.D.; Beta, T. Evaluation of antioxidant activity and electronic taste and aroma properties of antho-beers from purple wheat grain. J. Agric. Food Chem. 2007, 55, 8958-8966.

14. Beta, T.; Nam, S.; Dexter, J.E.; Sapirstein, H.D. Phenolic content and antioxidant activity of pearled wheat and roller-mill fractions. Cereal Chem. 2005, 82, 390-393.

15. Huang, D.; Ou, B.; Hampsch-Woodill, M.; Flanagan, J.A.; Prior, R.L. High-throughput assay of oxygen absorbance capacity (ORAC) using a multichannel liquid handling system coupled with a microplate fluorescence reader in 96-well format. J. Agric. Food Chem. 2002, 50, 4437-4444.

16. Chiremba, C.; Rooney, L.W.; Beta, T. Microwave-assisted extraction of bound phenolic acids in bran and flour fractions from sorghum and maize cultivars varying in hardness. J. Agric. Food Chem. 2012, 60, 4735-4742.

17. Hirawan, R.; Ser, W.Y.; Arntfield, S.D.; Beta, T. Antioxidant properties of commercial, regular- and whole-wheat spaghetti. Food Chem. 2010, 119, 258-264.

18. Hirawan, R.; Diehl-Jones, W.; Beta, T. Comparative evaluation of the antioxidant potential of infant cereal produced from purple what and red rice grains and LC-MS analysis of their anthocyanins. J. Agric. Food Chem. 2011, 59, 12330-12341.

19. Chandrika, M.L.; Shahidi, F. Importance of insoluble-bound phenolics to antioxidant properties of wheat. J. Agric. Food Chem. 2006, 54, 1256-1264.

20. Liu, Q.; Qiu, Y.; Beta, T. Comparison of antioxidant activities of different colored wheat grains and analysis of phenolic compounds. J. Agric. Food Chem. 2010, 58, 9235-9241.

21. Li, W.; Beta, T. Flour and Bread from Black-, Purple-, and Blue-Colored Wheats. In Flour and Breads and Their Fortification in Health and Disease Prevention; Preedy, V.R., Watson, R.R., Patel, V.B., Eds.; Academic Press: London, UK, 2011; pp. 59-67.

22. Juhasz, M.; Kitahara, Y.; Takahashi, S.; Fujii, T. Thermal stability of vitamin C: Thermogravimetric analysis and use of total ion monitoring chromatograms. J. Pharm. Biomed. Anal. 2012, 59, 190-193.

23. Lavelli, V.; Hidalgo, A.; Pompei, C.; Brandolini, A. Radical scavenging activity of einkorn (Triticum monococcum L. subsp. monococcum) wholemeal flour and its relationship to soluble phenolic and lipophilic antioxidant content. J. Cereal Sci. 2009, 49, 319-321.

24. Mpofu, A.; Sapirstein, H.D.; Beta, T. Genotype and environmental variation in phenolic content, phenolic acid composition, and antioxidant activity of hard spring wheat. J. Agric. Food Chem. 2006, 54, 1265-1270.

25. Mpofu, A.; Beta, T.; Sapirstein, H.D. Effects of Genotype, Environment and Genotype $\times$ Environment Interaction on the Antioxidant Properties of Wheat. In Wheat Antioxidants; Yu, L., Ed.; John Wiley and Sons Inc.: Hoboken, NJ, USA, 2007; pp. 24-41. 
26. Liyana-Pathirana, C.M.; Shahidi, F. Antioxidant and free radical scavenging activities of whole wheat and milling fractions. Food Chem. 2007, 101, 1151-1157.

27. Ou, B.; Huang, D.; Hampsch-Woodill, M.; Flanagan, J.A.; Deemer, E.K. Analysis of antioxidant activities of common vegetables employing oxygen radical absorbance capacity (ORAC) and ferric reducing antioxidant power (FRAP) assays: A comparative study. J. Agric. Food Chem. 2002, 50, 3122-3128.

28. Lin, L.; Liu, H.; Yu, Y.; Lin, S.; Mau, J. Quality and antioxidant property of buckwheat enhanced wheat bread. Food Chem. 2009, 112, 987-991.

29. Yilmaz, Y.; Toledo, R. Antioxidant activity of water-soluble Maillard reaction products. Food Chem. 2005, 93, 273-278.

30. Manzocco, L.; Calligaris, S.; Mastrocola, D.; Nicoli, M.C.; Lerici, R.C. Review of non-enzymatic browning and antioxidant capacity in processed foods. Trends Food Sci. Technol. 2001, 11, 340-346.

31. Michalska, A.; Amigop-Benavent, M.; Zielinski, H.; del Castillo, M.D. Effect of bread making on formation of Maillard reaction products contributing to the overall antioxidant activity of rye bread. J. Cereal Sci. 2008, 48, 123-132.

32. Moore, J.; Yu, L. Methods for Antioxidant Capacity Estimation of Wheat and Wheat-Based Food Products. In Wheat Antioxidants; Yu, L., Ed.; John Wiley \& Sons, Inc.: Hoboken, NJ, USA, 2008; pp. 118-166.

33. Revanappa, S.B.; Salimath, P.V. Phenolic acid profiles and antioxidant activities of different wheat (Triticum aestivum L.) varieties. J. Food Biochem. 2011, 35, 759-775.

34. Gasztonyi, M.N.; Farkas, R.T.; Berki, M.; Petroczi, I.M.; Daood, H.G. Content of phenols in wheat as affected by varietal and agricultural factors. J. Food Comp. Anal. 2011, 24, 785-789.

35. Hung, P.V.; Maeda, T.; Miyatake, K.; Morita, N. Total phenolic compounds and antioxidant capacity of wheat flours by polishing method. Food Res. Int. 2009, 42, 185-190.

36. Bunzel, M.; Ralph, J.; Lu, F.; Steinhart, H. Lignins and ferulate-coniferyl alcohol cross-coupling products in cereal grains. J. Agric. Food Chem. 2004, 52, 6496-6502.

37. Klepacka, J.; Fornal, L. Ferulic acid and its position among the phenolic compounds of wheat. Crit. Rev. Food Sci. Nutr. 2006, 46, 639-647.

38. Sun, J.; Liang, F.; Bin, Y.; Lin, P.; Duan, C. Screening non-colored phenolics in red wines using liquid chromatography/ultraviolet and mass spectrometry/mass spectrometry libraries. Molecules 2007, 12, 679-693.

39. Brandolini, A.; Hidalgo, A. Wheat germ: Not only a by-product. Int. J. Food Sci. Nutr. 2012, 63, $71-74$.

40. Hung, P.V.; Hatcher, D.W.; Barker, W. Phenolic acid composition of sprouted wheats by ultra-performance liquid chromatography (UPLC) and their antioxidant activities. Food Chem. 2011, 126, 1896-1901.

(C) 2013 by the authors; licensee MDPI, Basel, Switzerland. This article is an open access article distributed under the terms and conditions of the Creative Commons Attribution license (http://creativecommons.org/licenses/by/3.0/). 